EGU21-11922

https://doi.org/10.5194/egusphere-egu21-11922

EGU General Assembly 2021

(c) Author(s) 2021. This work is distributed under

the Creative Commons Attribution 4.0 License.

\title{
Geographical traceability in grapes: possible applications of trace and ultratrace elements
}

\author{
Carmela Vaccaro ${ }^{1,2}$, Fabio Alessandro Faccia ${ }^{3}$, Luigi Sansone ${ }^{4}$, and Elena Marrocchino ${ }^{1}$ \\ 1 (mrrlne@unife.it) University of Ferrara, Department of Physics and Earth Sciences, via Saragat 144121 Ferrara, Italy \\ ${ }^{2}$ (vcr@unife.it) ISAC-CNR Institute of Atmospheric Sciences and Climate of the National Research Council of Italy, Via Piero \\ Gobetti, 101, 40129 Bologna, Italy \\ 3 (fabioelletipi@gmail.com) SOCOTEC ITALIA, Ferrara Department - via Annibale Zucchini 69, 44122 Ferrara, Italy \\ ${ }^{4}$ (Iuigi.salnsone@crea.gov.it) Agricultural Research Council, Viticulture Research Center CRA-VIT, Viale XXVIII Aprile 26, 31015 \\ Conegliano, Italy
}

In the last decades the demand for information and criteria, suitable for connecting products to their production regions, is becoming more urgent in order to protect the qualitative high-level productions by forgery. Wine is one of the products that could benefit of a scientific system of analysis able to define its production area. Features of the association between wine and territory are not only related to pedological but also to geographical aspects. Currently, several studies to define markers, such as isotopic ratios of $\mathrm{O}, \mathrm{C}$, and $\mathrm{N}$, able to identify types of wine has been carried out, but they are not suitable to univocally define a specific type of wine in particular due to the high variability of some factors (temperature, age of the vineyard, period of such us isotopic...). Several samples of soils and grapes have been collected within the narrow area, characterized by quite heterogeneous lithologies, of the Euganei Hills area (NE of Italy) in order to identify possible markers typical of the growing area. The concentration of 25 elements $(\mathrm{Na}, \mathrm{Mg}$, $\mathrm{Al}, \mathrm{K}, \mathrm{Ca}, \mathrm{V}, \mathrm{Cr}, \mathrm{Mn}, \mathrm{Fe}, \mathrm{Co}, \mathrm{Ni}, \mathrm{Cu}, \mathrm{Zn}, \mathrm{Ga}, \mathrm{Rb}, \mathrm{Sr}, \mathrm{Y}, \mathrm{Zr}, \mathrm{Nb}, \mathrm{Ba}, \mathrm{La}, \mathrm{Ce}, \mathrm{Nd}, \mathrm{Pb}, \mathrm{Th}$ ) have been determined on grapes by using ICP-MS and on soils by using XRF techniques. Moreover, grapes have been further refined and separated in two different fractions (one residual solid fraction and one liquid fraction). The concentration of $\mathrm{Pr}, \mathrm{Sm}, \mathrm{Eu}, \mathrm{Gd}, \mathrm{Tb}, \mathrm{Dy}, \mathrm{Ho}, \mathrm{Er}, \mathrm{Tm}, \mathrm{Yb}$ and Lu have been determined on both these fractions in order to implement and complete the distribution pattern of REEs in the samples. Areas with geochemically different soils have been identified and in each one of these areas have been collected grapes of Cabernet Franc and Cabernet Sauvignon. Moreover, in most areas, several cultivars have been collected in order to better understand how biological variables could affect the assimilation of chemical elements from soils. Chemical composition of the grapes' inorganic fraction seems more influenced by soils than by cultivar type. In fact, REEs distribution patterns tend to differ more considering the same cultivar grown in areas with different pedological features. 